\title{
A Stairway to the Stars: Monitoring Sustainability Performance in SMBs
}

\author{
David A. Robinson and Brad P. Nikolic \\ CQ University, Australia
}

\begin{abstract}
This article proposes a framework that can be used, or modified for use, as a mechanism to measure, evaluate and monitor progress in business sustainability. It draws upon previous change management models, such as 'Management by Objectives' (Lynch, 1977; Felix and Riggs, 1983) and 'Balanced Scorecard' (Kaplan and Norton, 1995), proposing a conceptual framework for the monitoring of business sustainability. The framework allows sustainability improvement to be monitored by means of a composite sustainability index derived from specific metrics appropriate to a range of prioritised strategic objectives. It then discusses the necessity for such a mechanism to be sufficiently robust in respect of seven contextual issues. It recommends that a firm's choice of sustainability performance measures and their relative priorities should be aligned with global, societal, external, industry, organisational, leadership and individual-personal contexts.
\end{abstract}

\section{Keywords}

Business sustainability, performance-monitoring

\section{Introduction}

\section{"Tell me how you'll measure me; and I'll tell you how I'll behave" (Eli Goldratt)}

Why is there tardiness among business leaders to give priority to sustainability? This paper assumes one of the reasons may be the absence of a sustainability performance monitoring mechanism in firms. What form should such a mechanism take and how can we be confident that it would induce the changes needed to influence businesses worldwide toward continued sustainability improvement?

Before exploring these questions it is necessary that we define what is meant by business sustainability. As a foundation the World Council for Economic Development definition of sustainable development has been adopted, i.e. development which "meets the needs of the present

Copyright (C) 2014 Victoria University. This document has been published as part of the Journal of Business Systems, Governance and Ethics in both online and print formats. Educational and non-profit institutions are granted a nonexclusive licence to utilise this document in whole or in part for personal or classroom use without fee, provided that correct attribution and citation are made and this copyright statement is reproduced. Any other usage is prohibited without the express permission of the publisher. without compromising the ability of future generations to meet their own needs." (United Nations Brundtland Report, 1987). Whilst we accept that all businesses must operate within the broad scope of global sustainable development, we also believe it is necessary to include the aspect of resiliency, which in essence refers to the firm's ability, whilst striving for economic success, to adapt to external

forces over which it has little or no control, and to play a role in the continuation of the ecosystem that sustains it. 
Any framework that purports to facilitate the monitoring of sustainability performance will of necessity be sufficiently robust to be applied across industries and cultures. The framework incorporates contextual issues drawn from the work of Early (1997) and others, namely global, societal, external, industry, organizational, leadership, and individual/personal.

\section{The Seven Contextual Issues}

These contextual issues are seen as concentric circles, the outermost circle being the global context, and the innermost being the individual or personal context. The seminal theories within each of these contextual planes will be well-known to scholars of leadership, change management and business strategy, so they are listed only briefly below. More attention will be paid later in this article to each of these areas of concern to sustainability leaders, to the extent that each relates to our proposed business sustainability monitoring framework.

1. Global context - i.e. the current systemic global 'shocks', including global warming, global financial crisis, carbon emissions, world poverty, over-population.

2. Societal context - e.g. tightness (Witkin and Berry, 1975), collectivism (Parsons and Shills, 1951), power distance (Hofstede, 1991), judgement (guilt or shame) (Earley, 1997), orientation (Hofstede, 1980), relationship to nature (Kluckohn and Strodtbeck, 1961)

3. External context: the political, economic, social, technological, environmental, legal and ethical issues that can impact business performance and sustainability.

4. Industry context, i.e. industry lifecycle, competitive rivalry, supply-side economics, demandside dynamics, substitute products and innovation (Porter, 2007).

5. Organizational context, including the physical, financial and technical resource base (said to provide short-term competitive advantage) as well as reputation, intellectual property and competencies such as governance structure, culture, rules and processes (essential for longerterm competitive advantage), (Barney, 2001). Financial considerations include budgetary constraints, investment, and expected returns. Intellectual Property includes innovation propensity, such as development and/or adoption of IT solutions. Technical aspects and current trends, such as electronic and audio-visual processes replacing face-to-face contact

6. Leadership context: Of particular importance to this paper is the ability of the business leader to create a 'vortex' that 'sucks in' participants. As such it focuses on the leadership styles known as ethical (Brown and Trevino, 2006), authentic (Bass and Avolio, 1993), charismatic (House, 2006), and transformational (Podsakoff, et. al., 1990).

7. Individual/Personal context: Whilst this paper does not purport to include personal psychological concepts, the necessity for business leaders to understand how some common problem areas pertaining to individual choices and personal commitment are important to ensure that any performance monitoring system takes account thereof. In this paper the following aspects are discussed: Self-concept regulation (Erez and Earley, 1993), self-identity (Hinkle and Brown, 1990), goal attainment (Locke and Latham, 1990), role expectations, specifically ambiguity (Katz and Kahn, 1978), entrepreneurial dilemmas (Robinson, Davidson, van der Mescht and Court, 2007), and career advancement considerations (Tajfel, 1978).

\section{Introducing the proposed model}

Based on the theoretical and applied knowledge available to them, the authors now proceed to propose a model that will be sufficiently flexible to incorporate the sustainability objectives specific to any small or medium business as well as to prioritize those and measure the firm's performance at regular intervals. The prioritization is achieved by assigning a relative weighting to each sustainability objective. The measurement of progress towards each objective is facilitated by the designation of metrics corresponding to particular levels of performance. The proposed model is illustrated by means of a worked example in the table below: 


\begin{tabular}{|c|c|c|c|c|c|}
\hline \multirow{2}{*}{\multicolumn{2}{|c|}{ Level accomplished }} & \multicolumn{4}{|c|}{ Prioritized Strategic Objectives (SOs) } \\
\hline & & \multirow{3}{*}{$\begin{array}{c}\text { SO } 1= \\
\text { e.g. recycle } 60 \% \text { of } \\
\text { solid waste } \\
1.5 \\
60 \%\end{array}$} & \multirow{3}{*}{$\begin{array}{c}\text { SO 2 = } \\
\text { e.g. reduce carbon } \\
\text { emissions by } 15 \% \\
4.0 \\
15 \%\end{array}$} & \multirow{3}{*}{$\begin{array}{c}\text { SO 3 }= \\
\text { e.g. switch to } 50 \% \\
\begin{array}{c}\text { renewable energy } \\
\text { sources }\end{array} \\
3.0 \\
50 \%\end{array}$} & \multirow{3}{*}{$\begin{array}{c}\mathrm{SO} 4= \\
\begin{array}{c}\text { e.g. reduce fresh } \\
\text { water consumption } \\
\text { by } 60 \%\end{array} \\
1.5 \\
60 \%\end{array}$} \\
\hline Weightir & /10: & & & & \\
\hline $\begin{array}{l}\text { Superlative level of } \\
\text { accomplishment }\end{array}$ & 10 & & & & \\
\hline $\begin{array}{l}\text { Distinctive } \\
\text { improvement }\end{array}$ & 9 & $50 \%$ & $14 \%$ & $45 \%$ & $54 \%$ \\
\hline $\begin{array}{c}\text { Creditable } \\
\text { improvement }\end{array}$ & 8 & $40 \%$ & $13 \%$ & $40 \%$ & $48 \%$ \\
\hline $\begin{array}{c}\text { Significant } \\
\text { improvement }\end{array}$ & 7 & $30 \%$ & $12 \%$ & $35 \%$ & $42 \%$ \\
\hline $\begin{array}{c}\text { Acceptable } \\
\text { improvement }\end{array}$ & 6 & $20 \%$ & $11 \%$ & $28 \%$ & $36 \%$ \\
\hline No improvement & 5 & $10 \%$ & $10 \%$ & $22 \%$ & $30 \%$ \\
\hline $\begin{array}{l}\text { A little worse than } \\
\text { last year }\end{array}$ & 4 & $9 \%$ & $9 \%$ & $16 \%$ & $24 \%$ \\
\hline $\begin{array}{c}\text { Unacceptably } \\
\text { worse than last year }\end{array}$ & 3 & $8 \%$ & $8 \%$ & $12 \%$ & $18 \%$ \\
\hline $\begin{array}{c}\text { Highly } \\
\text { unacceptable }\end{array}$ & 2 & $7 \%$ & $7 \%$ & $8 \%$ & $12 \%$ \\
\hline $\begin{array}{l}\text { Inexcusably poor } \\
\text { performance }\end{array}$ & 1 & $6 \%$ & $6 \%$ & $4 \%$ & $6 \%$ \\
\hline $\begin{array}{c}\text { Totally despicable } \\
\text { performance }\end{array}$ & 0 & Less than $5 \%$ & Less than $5 \%$ & $0 \%$ & $0 \%$ \\
\hline
\end{tabular}

Table 1: A Conceptual Framework for the Monitoring of Business Sustainability

Notes pertaining to the 'metrics' given as examples in the above table:

Weighting: the relative importance of each strategic objective vis-à-vis the others, collectively totaling 10 .

Level 10: performance consistent with the best in the world, country, or industry

Level 5: as per end of previous year's level of accomplishment

Level 1: performance is no better than the worst in the world, country, or industry

Level 0: performance is worse than the worst in the world, country, or industry

Levels 6 to 10: the 'carrot' - recognition, reward, career advancements ensue

Levels 2 to 4: the 'stick' - below this line means we have gone backwards since the previous year

The proposed sustainability management framework is designed to accommodate various necessary components of an effective performance management tool. Strategic objectives should be specific, with a realistic expectation of accomplishment, and designated accountability for achievement within the forthcoming year. The strategic objectives should be linked directly with the business strategies. A maximum of five strategic objectives per year is recommended. Each of these heads one column, which may be weighted according to strategic objective's relative importance in that particular year. 
The total of the weights must be 10. Priorities may be re-established each year in line with the company's strategic plan. This means that some of the objectives may be replaced by measures considered more appropriate to the firm's current stage of development and may be allotted higher or lower priorities by varying their respective weighting. Each of the selected objectives is supported by a finite measurement, or 'metric'. Accountability for each of these outcomes may be allocated to a functional area of the business, or a sustainability project manager and the relevant cross-functional team.

The performance levels are depicted on the vertical axis. A ten point scale is forged in the following way: Level 10 represents the superlative performance, i.e. the current best-in-world or industry, so called 'state of the art'. Level 5 represents the company's current level of performance. Levels 6 to 9 are calculated so as to represent the intermediate graduations spanning levels 5 and 10 in equal steps. Level 0 would be regarded as 'disgraceful', or akin to the worst imaginable performance. Levels 1 to 4 inclusive are calculated, again as equivalent graduated steps between 0 and 5 .

The company's overall sustainability performance is measured by monitoring the actual metric within each strategic objective (column), then locating its corresponding 'level'. Finally, for each column, the performance 'level' is multiplied by the respective weight, and the resultant composites added together to give an overall sustainability percentage.

Performance evaluation can be facilitated as follows: In the overall result, if the company has performed above $50 \%$, there is net improvement over the previous year. Conversely, if the overall result is less than $50 \%$, the company's sustainability performance has diminished relative to the previous year. Specifically, if any particular column scored a level below 5, then the company has reduced sustainability in that strategic area. Most importantly, improved performances are evident as their column scores will be greater than 5. Appropriate and culturally-aligned incentives, rewards and disincentives may be applied based directly on these results. The levels may be recalibrated annually, such that the most recent year's performance in each of the strategic objective's metrics is placed at level 5. More dramatic adjustments to the framework can be brought about by rethinking the strategic objectives, or by introducing alternative metrics where needed.

Adoption of sustainability monitoring into the company culture will occur as the monitoring and evaluation process is repeated, the results reported, and the corresponding rewards and punishments are seen to be taken into account when job promotions, incentives, and investment decisions are considered

By way of illustration, let us suppose that our firm achieves the following results in the current year:

\begin{tabular}{|c|c|c|c|c|}
\hline $\begin{array}{l}\text { SO } 1 \\
\text { recycling of solid } \\
\text { waste Goal } 60 \% \\
\text { weight } 1.5 \\
\text { result } 30 \%=\text { level } 7 \\
\text { contribution: } 7 \times 1.5 \\
=10.5\end{array}$ & $\begin{array}{l}\mathrm{SO} 2= \\
\text { Reduction in carbon } \\
\text { emissions Goal15\% } \\
\text { weight } 4.0 \\
\text { result } 11 \%=\text { level } 6 \\
\text { contribution: } 6 \times 4.0 \\
=24.0\end{array}$ & $\begin{array}{l}\text { SO } 3= \\
\text { Energy sources } \\
\text { Goal } 50 \% \text { renewable } \\
\text { weight } 3.0 \\
\text { result } 40 \%=\text { level } 8 \\
\text { contribution: } 8 \times 3.0 \\
=24.0\end{array}$ & $\begin{array}{l}\mathrm{SO} 4= \\
\text { Reduce fresh water } \\
\text { usage by } 60 \% \\
\text { weight } 1.5 \\
\text { result } 36 \%=\text { level } 6 \\
\text { contribution: } 6 \times 1.5 \\
=9.0\end{array}$ & $\begin{array}{c}\text { Overall } \\
\text { Sustainability } \\
\text { Performance } \\
\text { Composite Score }\end{array}$ \\
\hline
\end{tabular}

The firm's overall sustainability index is $67.5 \%$ for the current year, which represents an improvement upon the previous year (i.e. $67.5 / 50$, as the previous year's score would have been $50 \%$ after recalibration). For the forthcoming year, the strategic objectives may be changed, the metric could be altered, or at the very least the levels would be adjusted by recalibrating the existing metrics so that the most recent year's results are portrayed at level five. 
Now that the mechanism is explained, we turn our attention to ensuring that the proposed framework is sufficiently robust to adequately facilitate the adoption of all seven of the relevant contextual issues, as listed earlier in the article. These will be discussed one at a time.

\section{Global context}

Economies around the globe, beset by the aftermath of a global financial crisis, face severe constraints on financial performance. Perhaps an over-emphasis on financial performance has been a contributing factor to the lack of commitment to long-term business sustainability. Business leaders are now faced with the prospect of adopting a more balanced approach to the measurement and evaluation of business performance.

The spotlight has turned in recent years to carbon emissions, which have reached alarming proportions across industrialised regions of the world. It is widely believed that carbon emissions are directly correlated with global warming, though some may contest the cause and effect model (Heimann \& Reichstein, 2008). One proposed 'solution' is a carbon emissions taxation, perhaps a globally centralised system, which may unite the world through a common 'currency' and a singular measurement system with a financial effect on businesses, thereby ensuring that at least one aspect of global sustainability becomes a standard item at every board meeting (Roy, Kerry \& Kip, 1995).

Outside of the realm of most businesses, other pertinent global issues include over-population and poverty, as well as deforestation and species extinction. Any business that impacts those issues would do well to also include improvement targets in its sustainability evaluation model. Potentially, one of the following strategic objectives in the global context could be selected by a firm: decrease in carbon emissions (targeted percentages listed in the ten point scale), renewable energy consumption (e.g. percentage of total energy consumption), number of approved projects (or annual amount invested) to improve the company's contribution in the realm of environmental sustainability.

\section{Societal context}

The societal context is discussed under six sections, each referring to a key and well-established construct, namely tightness, collectivism, power distance, judgement, orientation and relationship to nature.

\section{Tightness}

Tightness refers to the extent to which rules and norms are present and enforced within a given society (Witkin and Berry, 1975). This is a relevant construct in the context of sustainability as a tight culture would be more conducive to the central control of individual actions (Glenn and Glenn, 1981); Triandis, 1989) as individuals are expected to conform and 'psychological differentiation' is discouraged (Witkin and Goodenough, 1977). Conversely, a 'loose' culture would require a more decentralised approach. For that reason, a sustainability performance monitoring framework must remain flexible and adaptable.

\section{Collectivism}

Collectivism, a term made popular by Hofstede $(1980,1991)$, was first conceptualised much earlier as the tendency of some cultures to pursue collective interests in preference to individual interests (Parsons and Shils, 1951). Within such a culture it is incumbent upon the individual to find favour with peers, even to the extent that an individual's self-image may be dependent on their perceived degree of acceptance by the 'in-group', a concept first explored by Social Identity Theory (Tajfel et. al., 1971). Three levels of self-categorisation were identified, in which the super-ordinate level applies 
to the common features one shares with fellow humans (Tajfel, 1978). In the context of sustainability this is highly relevant, as we are seeking to create a new cognitive system in which sustainability issues will need to become the focus of in-group activity.

\section{Power distance}

Power distance refers to the degree of inequality, or relative distribution of power, in a given society (Hofstede, 1991) The construct actually 'captures the degree of acceptability of power differentials' (Earley, 1997: 28), which in turn creates perceived legitimacy among so-called powerful individuals who exert influence on the actions of others. The power-distance construct has relevance to the sustainability monitoring process in ways similar to 'tightness' in that it impacts the extent to which employees, teams and particularly those employed in managerial roles within a given business may be willing to accept the dictates of senior executives with regard to the setting of sustainability management targets and monitoring mechanisms.

\section{Judgement}

The nature of people's relationship to their own moral commitment was first studied by Mead (1928) as a so-called 'guilt or shame' construct. According to Earley (1997), persons in a guilt-based culture take personal responsibility for inappropriate responses to societal issues, while in a shame-based culture individuals simply experience shame for what they see as externally imposed negative consequences emanating from issues they believe to be outside of their control We regard this aspect as pertinent to issues of sustainability due to the significant occurrence in the rhetoric of generation $\mathrm{X}$ and $\mathrm{Y}$ members appearing to indicate a growing inference that they 'blame' previous generations for not sufficiently addressing global sustainability issues (notwithstanding their willingness to embrace the positive effects brought about by industrialisation, immunisation and other more positive influences. As the new generation must ultimately take up the challenges of solving pollution, global warming and over-population, they will need to adopt the approach of 'us against the problem', rather than us against them' To achieve that change, an open agenda and transparent mechanisms such as the proposed framework will undoubtedly become essential.

\section{Orientation}

Hofstede's (1980) conceptualisation of masculinity versus femininity is often mistakenly associated with gender inequality when in fact it refers to the cultural orientation such as competitiveness and efficiency (the so-called masculine traits), as opposed to the co-operation and co-development (socalled feminine traits). It is clear that global sustainability demands a combined, coordinated and cooperative effort that is distinctly 'feminine' in orientation. In order to be successful, it also needs to be integrated into business environments that still remain predominantly 'masculine' in orientation.

\section{Relationship to nature}

The relationships that people have toward nature is an interesting and pertinent cultural dimension, construed by Kluckohn and Strodbeck (1961) as a tri-partite construct. Some people attempt to execute mastery over nature, harnessing it through technology, expertise and effort (typically the socalled Western cultures); others seek to find balance with nature so as to peacefully co-exist (typically the Pacific-rim cultural groups); a third are subjugated to it, destined to be controlled by nature, thus believing that any effort to change it is futile (typically a Middle-Eastern philosophy), according to Lane and DiStephano (1992). Where sustainability matters are concerned, businesses must accept responsibility for the impact of their actions on nature. To have global relevance, and so as not to alienate any sub-group, businesses need to adopt a sustainability performance monitoring and evaluation mechanism that can synergise all three sides of the tripartite model of man's relationship to nature. 


\section{External context}

No business can ignore the opportunities and threats emanating from the external environment. Indeed, achieving organisational effectiveness depends on how well the business adapts to its external environment (Yukl, 2008). While this article addresses each of the six commonly associated external factors under the acronym, PESTEL, it also adds a seventh, which is considered highly relevant to the subject of sustainability, namely Ethics:

Political - all issues of global significance tend to become politicised (ref) and we already see that sustainability falls into that category, as some governments push for environmental responsibility and seek to implement policies directed thereto, while others choose to ignore the issue.

Economic - in businesses where historically the ultimate measure of success has been the 'bottom line' (ref), external factors are assessed as opportunities or threats according to their propensity to impact profits, either positively or negatively. In order for sustainability to become a fixture on the board meeting agenda, it needs have a relatable and measurable economic impact at the level of the firm.

Social - Societal influences, biases and idiosyncratic cultural constructs appear to be mutating at accelerated rates due to mass communication, world-wide travel, and indeed globalisation in general. Companies are seldom mono-cultural and ethno-centricity appears doomed to history, as staffing becomes increasingly polymorphous, resulting in a level of cultural complexity never before imaginable.

Technological - again changing at an alarming rate, every new technology brings with it sustainability challenges. History has already proven that yesterday's solutions give rise to tomorrow's problems, so it seems we are locked into a continuous cycle of problem - solution problem, where technology is concerned. In modern times there is no doubt a greater reliance on technology, and with that a greater propensity to upset the delicate balance of ecology, perhaps unknowingly until future generations have to deal with its long-term negative effects. We would offer the field of gene morphology as an example.

Environmental - Let us consider just one environmental issue that is current and pertinent, namely climate change. So far only the global bankers and G20 politicians have seen an opportunity therein, namely a carbon tax. For the rest, global warming remains a horrendous prospect, threatening to change our habitat irreversibly with seemingly dire consequences.

Legal - There are daily reports of pending legislation surrounding sustainability issues, many of which will impact the competitive strategies of businesses falling under their jurisdiction.

Ethical - This factor has been added on account of its pertinence to sustainability, as we believe every firm needs to examine its 'conscience' and take necessary steps to ensure that it acts in accordance with the ethical principles it purports to uphold. By way of example, we offer the following two scenarios: The first is a company that has made fortunes by manufacturing and selling asbestos-based products, but now realises their products could contribute to life-shortening non-communicable disease in humans. The second is a company that has billions of dollars invested in mining sites around the world, but must confront the criticism that their continued removal of organic metals from the earth's crust may well prove at some future date to have adversely affected its gravitational, magnetic and/or orbital field, with disastrous and catastrophic consequences for human existence.

It is generally accepted that SMBs are impacted by relevant external factors. The potential effects prompt them to proactively consider strategies that exploit opportunities and neutralise threats. Industries and firms also need to be aware that, in a sustainability sense, there now exists an unavoidable symbiosis between the external and internal environments, i.e. certain strategies that they may decide to pursue will have an effect on external factors. The realisation that your firm is not only affected by the problem, but also contributing to that problem (like the motorist whose vehicle forms 
part of a traffic jam), may afford sustainability issues a higher priority when strategic options are evaluated. Since all firms exert some degree of influence upon the collective external environment, however minute that influence may appear, there is at the very least the motivation of self-interest for taking an 'inside-out' look at the seven factors described above.

Some suggested measures that could underscore strategic objectives set by the firm in this arena are the following: Participation at policy-making levels, ethical pricing processes in imperfect markets, responsible adoption of technology.

\section{Industry context}

Sustainability issues undoubtedly impact some industries more than others. Whilst it is obvious that retail and service-related industries thrive on population growth, it may be less obvious that the agricultural sectors of the modern-day global economy are simply unable to keep up with demand. And while most countries are already on a developmental trajectory that will most certainly render their economies largely dependent on increased tertiary sector activity, there will always be a need to supply those economies with goods sourced from the primary and secondary economic sectors.

Michael Porter (1986) advises firms to consider the likely impact of industry forces. It will be incumbent upon industry leaders to assess industry life-cycle, competitive rivalry, supply-side economies, demand-side considerations including global distribution and logistics, as well as innovative new and substitute products, from the modern-day perspective of sustainability.

We offer it as an inevitable consequence of globalisation that industry lifecycles will shorten and competitive rivalry will become fiercer than before, as firms endeavour to capture market share during the (diminished-duration) high-growth phase of each industry's respective lifecycle. Substitute products and technologies will continue to increase at an accelerated rate, due to the ever-increasing propensity for technological innovation.

In view of the above-mentioned industry factors, the following examples of strategic objectives are offered for consideration and possible inclusion in the firm's sustainability framework: technologymaker or taker (degrees of improvement), innovator or imitator (investment in research and development), supply chain and distribution channel conflict management processes (index of cooperation/complaints).

\section{Organizational context}

Barney's (2001) Resource-Based View of the firm has been widely regarded as a way to analyse a firm's internal effectiveness. As well as providing a concise acronym (PROFIT), it reminds us to also distinguish between the short-term competitive advantages that can be derived from the firm's physical, financial and technical strengths, in contrast to the more sustainable competitive advantages associated with the firm's reputation, organisational capability and intellectual property. We discuss each of these now, beginning with the short-term internal factors and then moving on to the longterm:

Physical presence and Product - the firm is known to its market by its physical presence or location, and by its product range. Today there is increased pressure to select locations that do not adversely affect indigenous bio-diversity and there is added pressure on products to be environmentallyfriendly, as in recycle-able, bio-degradable, organically-produced or treated, not tested on animals etc. Financial - As every firm has budgetary constraints on investments and expenditures, added capital requirements to address issues of sustainability will be subject to careful planning and approval 
requirements to address issues of sustainability will be subject to careful planning and approval procedures and will incur a necessary and unavoidable lag time before they can be implemented. The firms that become first-movers in sustainability issues may enjoy some competitive advantage from their efforts before others in their industry catch up.

Technical - the firm's resources, machinery, engineering and information systems are the tangible assets that render it capable of producing economies of scale and scope through efficiency and responsiveness hat enhance its competitive advantage in its chosen markets. Technical traditions and habits that negatively impact the firm's sustainability, however, need to be reformed.

Reputation - a company's reputation is derived from its historical legacy and its current positioning in the marketplace. Branding plays a prominent role in building a firm's reputation. Nothing can tarnish a brand more than it being associated with a scandalous event or incident. In current times, the apparent disregard for, or violation of, any principle of global sustainability can do irreparable harm to the brand. Examples of this include the accusations against Nike's alleged use of cheap labour in Thailand, and the practice of developed nations dumping their unwanted waste in less developed countries.

Organization - this aspect encompasses all of the intangible assets that create a firm's organisational capability, specifically the firm's governance structure and company culture. Organisation culture may essentially be described by the following ten processes (Robinson, 2008): the type of people employed, the way people are selected, how their further development is facilitated, what they are expected to do to earn promotion within the firm, how people's performance is measured/evaluated, how their efforts are rewarded and recognised, what type of organisation structure is prevalent, what style of management is preferred, how decisions are made, and how the firm defines its future. The exact way in which each of the ten processes is played out is unique to every firm. Essentially though, they ought to be 'in sync', i.e. balanced and congruent with the firm's development or life-cycle trajectory and its current progress toward its ultimate vision (Robinson, 2010). Integral to these is the social discourse within the firm, giving due regard to organizational politics (Mayes \& Allen, 1977) in particular what characterises in group, as opposed to out-group, loyalties and memberships (Erez and Earley, 1993).

Senge (1991) established the concept of the learning organisation. This concept implies the setting of a work environment where people are encouraged to constantly develop their capabilities and produce the results they truly desire, while working towards a common goal. Learning is seen as an ongoing process that builds upon both success and failure. As in a military context, after-action-reviews are regarded as an effective way for business leaders to periodically evaluate progress toward business goals as well as their effectiveness. (Gino and Pisano, 2011:73). Similarly, Hollman and Tanzik (1977) suggested that objectives have to be periodically re-assessed.

Intellectual Property and Innovation Propensity - herein lies the hidden store of ammunition with which the firm takes confidence in its ability to withstand challengers to its market success. It is logical though that innovation must be purposeful and strategically sustainable as intellectual property, in order to produce profitable returns.

The following sustainability objectives are offered as examples of how internal factors can be incorporated into the proposed framework: Synchronicity of firm's internal processes (can be measured in terms of a congruency index), internal promotions (e.g. percentage of external appointments), brand equity, financial ratios, intellectual property registrations. 


\section{Leadership Context}

Collective learning focused on improving long-term performance is more likely to occur when key stakeholders agree that it is important and will help them to achieve their individual objectives. (Yukl, 2009:52)

Four types of leadership are discussed, namely transformational, authentic, ethical, charismatic. Once a strategic direction is formulated its implementation requires change leadership. We draw attention in this article to four types of change leadership in particular, namely authentic leadership, ethical leadership, transformational leadership, and charismatic leadership. Leaders also increase organizational performance by exerting influence upon performance determinants. Examples of such influences include:

- Displaying certain patterns of leadership behaviour in interactions with subordinates, peers, and outsiders

- Decisions on management programs, systems and organizational structure, that indicate bias or favouritism

- Determining the competitive strategy for the organization

As effective strategic leadership demands consistency and perceived fairness in the implementation of decisions (Yukl, 2008), the Sustainability Framework offers an opportunity for openness and transparency in strategic leadership decision.

\section{Authentic Leadership}

Authentic leaders act in ways that are true to their core beliefs and values, due to self-awareness and self-regulation. They therefore exert positive influences on followers, who aspire to similar values, a process that has become known as relational transparency. Relational transparency results in a trust relationship between leader and follower (Avolio, Walumbwa and Weber, 2009).

Self-awareness is a substantial factor for being authentic. This means not only knowing one's strengths but also being aware of one's weaknesses (George, 2003). A Sustainability Framework needs to incorporate values and beliefs of the authentic leader and use these as a benchmark for performance.

\section{Ethical Leadership}

Ethical leaders lead by example according to what is moral and in line with an organization's ethical context. Ethical leadership may be based on consequentialism, deontology or virtues. Its aim is to increase awareness of followers' own behaviour, while holding them accountable for their own decisions, actions and behaviour (Brown and Trevino, 2006).

Ethical leaders will not only lead in line with a code of ethics, but by example according to their own ethical values and beliefs. According to Brown and Trevino (2006) there are three situational factors that affect the ethical leader, namely: ethical role modelling, the extent to which he/she develops their organization's ethical context, and the moral intensity of the business issues faced.

With a reward system that is seen to be linked to right action, followers are more likely to act in accordance with what is right. Furthermore, when followers are treated with fairness and consideration a social exchange relationship develops between leader and follower based on trust, which in turn further enhances the willingness of followers to support an ethical leader (Walumbwa and Schaubroeck, 2009). 
The positive business outcome of ethical leadership is therefore that it increases productive follower behaviour. A sustainability monitoring framework should assist in improving the performances of individual and business units if the goals and measures are truly in line with organizational values.

\section{Transformational Leadership}

Transformational leaders influence organizational culture by realigning it with the new vision. Their aim is to improve followers' level of performance to meet changed expectations (Bass and Avolio, 1993). According to Bass and Steidelmeier (1999: 181) 'transformational leadership must be grounded in moral foundations' and is made up of four components, namely, 'idealized influence, inspirational motivation, intellectual stimulation, and individualized consideration'.

Through idealized influence the leader can aim for high performance standards, which can be monitored by the sustainability framework. Inspirational motivation engages followers in new standardised goals, which would become embedded within the sustainability framework. Intellectual stimulation occurs as leaders allow followers to participate in the target-setting process, thereby ensuring that all employees understand why those specific performances have been chosen to be measured with the sustainability framework and how they all collectively link with the vision and implemented actions. With individualized consideration leaders evaluate organizational performance on at an individual level, not just at an overall company level, thereby ensuring that the unique potential of each member of the organization is harnessed.

Transformational leaders are able to get their followers to perform beyond the level of expectation by building relationships based on mutual trust and respect, which in turn enhances followers' work attitudes and satisfaction levels (Podsakoff, MacKenzie, Moorman, and Fetter, 1990). In summary, the proposed Sustainability Performance Monitoring Framework should be useful in transformational leadership as it aids the monitoring and evaluation of both individual and group performance based on a standardised set of parameters.

\section{Charismatic Leadership}

Charismatic leaders help their followers internalize beliefs by communicating an aspirational vision of the firm's future and ideology. Followers of the charismatic leader will show loyalty and will be more willing to implement their leaders' decisions without questioning their self-interest. (House, 2006; Howell and Shamir, 2005). What is not intended though is blind obedience to the leader.

The socialized charismatic leader is concerned about the common wellbeing of his followers, addressing their needs and motivating them to work towards a common goal. A Sustainability Framework will empower them to do so, without expecting blind submissiveness towards a set goal by making goals specific and measurable. Today's turbulent and unstable environment requires leaders to be flexible. It is therefore important that they understand the complexities associated with performance management (Yukl, 2008). Perhaps it is most significant that as far back as 1947, Weber (in Early, 1997:113) stated that "the role of charismatic authority is to create and institutionalize new orders of rules, traditions and procedures that eventually supplant the charismatic leader".

\section{Individual-Personal Context}

Individuals are social actors who respond to both external and internal stimuli, thereby actively engaging in the environment, enacting aspects of their social milieu, and engaging in sense-making actions in order to interpret observed patterns (Early, 1997). 


\section{Self-concept regulation}

All people have a self-concept regardless of cultural or societal background. The self-concept defines an individual and profoundly influences their responses to internal and external stimuli (Wyer and Srull, in Early, 1997). The self-concept enables individuals to find and define their positions within given organisational and social systems. Self-concept is such a strong influencer that, at any given time an individual's personality is affected by it (Kihlstrom et al., 1988). This resultant working self, i.e. the part of the self that is active at any particular time, interacts directly with the social environment (Early, 1997). Furthermore, several psychological processes actively control self-concept (Erez \& Early, 1993). These processes involve setting goals, developing and selecting strategies to accomplish the goals, evaluation of priorities, and self-monitoring of goal achievement (Locke \&Latham, 1990). The self-concept forms a link between individual behaviour, the social context, and the cultural setting.

\section{Self Identity}

Self-identity determines how individuals define themselves among others. According to Breckler and Greenwald (in Sorrentino and Higgins, 1986) there are three sources, which have influence on selfidentity, namely public, private and collective.

The public aspect of self regulates how well an individual is capable of adopting social rules and demonstrating that one is socially acceptable. The private aspect of self determines behavioural standards, goal setting and responsibility for personal outcomes based on internalized values and standards. Finally the collective aspect of the self focuses on how an individual can contribute to the common good (Hinkle \& Brown, 1990; Stryker, 1980). It has already been noted that social identity theory implies that the self-image of an individual is affected by intergroup comparisons. This proposition was supported by the findings of Oakes and Turner (1980) regarding the negative effects to self-image resulting from 'out-group discrimination'. Turner's (1985) Self Categorization Theory (SCT) underlines the concept of intergroup behaviour and social identity. According to Turner (1985, in Early, 1997:106), SCT proposes, inter alia, that: 'self-concept is the fundamental component of a cognitive system, cognitive representations of self may take the form of self-categorizations, (and that) self-categorizations exist as part of a hierarchical system'. Furthermore, it has been noted that group formation appears spontaneously from a given context and that 'individuals are motivated to maintain a positive self-evaluation ... through a comparison of self and other member characteristics ... of the next higher level' (Turner et al., 1987, in Early, 1997:106). We assume that these principles apply to modern-day work places, therefore in order to make sustainability one of the constructs of self-categorisation, it would have to be perceived as a focus of those at the higher levels of an organisation.

\section{Goal Attainment}

Human behaviour is intended to be purposeful, therefore defined goals potentially enhance the social actors' performance (Locke and Latham 1990).

To achieve business goals, performance must be monitored and evaluated. To set certain benchmarks for task performance a goal should be timely distinguished into short-term and long-term goals. Additionally to keep the social actor motivated in the goal attaining process, goals should neither be too easy nor appearing to be impossible to achieve. 
While top management carries the primary responsibility for determining what programs are relevant, coordinated efforts by leaders at all levels in the organization are necessary to ensure that programs are effectively implemented (Yukl, 2008, 712). The Sustainability Framework is a measurement tool, which can assist managers to focus individuals and business units.

\section{Role Expectations}

In an organization every individual has a role. Certain expectations come with that role.

Role conflicts arise when a social actor is required to solve multiple demands simultaneously. For example, a manager who is charged with the responsibility for two competing projects, though both may bring overall benefits to the organization.

Role difficulties can also arise from ambiguous tasks, i.e. where the required outcome is ill-defined, which then lead to demotivation and loss of strategic direction (Early, 1997). An example of ambiguous tasks would be a car manufacturer who invests in high performance race car production, while, at the same time, investing in alternative energies. The implementation of the proposed Sustainability Monitoring and Evaluation Framework will aid focus and negate ambiguity as it, not only ensures that the five strategic sustainability objectives are clearly stated and their respective metrics are transparent, but also, by the mathematics of its evaluation process, it offsets the progress made toward strategic objectives by retrogression in others. And their respective weightings.

\section{Conclusion}

This paper has proposed a Sustainability Monitoring and Evaluation Framework and stressed the importance of flexibility and adaptability according to the changing needs and priorities of organisations. It has been shown that the proposed model meets what are considered by the authors as the essential criteria of an effective mechanism. Specifically, it allows business leaders to involve staff in the decisions regarding key strategic sustainability objectives and the monitoring of progress toward their achievement. As a participative process it can also serve to motivate and empower individuals and groups within the firm, thereby strengthening ethical, authentic, charismatic and transformational leadership processes. It allows sufficient scope for the nurturing of self-concept, selfidentity, role expectations, and goal achievement among individuals and organisational groups. It appears sufficiently robust to incorporate relevant concerns emanating from the firm's external, industry, and organisational contexts, by virtue of a periodic, suggested annual, adjustment in performance targets and their respective weightings. 


\section{References}

Avolio, B.J. \& Gardner, W. 2005. Authentic leadership development: Getting to the root of positive forms of leadership. The Leadership Quarterly, 16, 315-338.

Avolio, B., Walumbwa, F., \& Weber, T.J. 2009. Leadership: current theories, research, and future directions. Annual Review of Psychology, 60, 421-449.

Barney, J. B. 2001. Is the resource-based view a useful perspective for strategic management research? Yes. The Academy of Management Review, 26(1):41-56

Bass, B.M., \& Avolio, B.J. 1993. Transformational leadership and organizational culture. Public Administration Quarterly, 17, 112-121.

Bass, B.M., and Steidelmeier, P. 1999. Ethics, Character, and Authentic Transformational Leadership Behavior. The Leadership Quarterly, 10, 181-217.

Bird, F., \& Smucker, J. (2007). The Social Responsibilities of International Business Firms in Developing Areas. Journal of Business Ethics, 73(1), 1-9.

Brown, M.E., and Trevino, L.K. 2006. Ethical leadership: a review and future directions. The Leadership Quarterly, 17, 595-616.

Earley, P. C. 1997. Face, Harmony and Social Structure. New York: Oxford University Press.

Erez, M. \& Earley, P. C. 1993. Culture, Self-Identity and Work. New York: Free Press.

Felix, G. H. \& Riggs, J. L. 1983. Productivity measurement by objectives. National Productivity Review, 2(4):386-393.

George, B. 2003. Authentic leadership: rediscovering the secrets to creating lasting value. San Francisco: Jossey-Bass.

Goldratt, E. \& Cox, J. 1992. The Goal - a process of ongoing improvement. (R2e). New York: North River Press.

Gino, F. \& Pisano, G.P. 2011 "Why Leaders Don't Learn From Success". Harvard Business Review $89,68-74$

Glenn, E. S. \& Glenn, C. G. 1981. Man and Mankind: Conflicts and communication between cultures. Norwood: Ablex.

Heimann, M. \& Reichstein, M. 2008. Terrestrial ecosystem carbon dynamics and climate feedbacks. Nature: 451 (289-292).

Hinkle S. \& Brown, R. J. 1990. Intergroup comparisons and social identity: Some links and lacunae. In Abrams, D. \& Hogg, M. A. (Eds). Social Identity Theory: Constructive and Critical Advances. New York: Springer-Verlag.

Hofstede, G. 1991. Culture and Organizations: Software of the mind. London: McGraw-Hill.

Hofstede, G. 1980. Culture's Consequences: International differences in work-related values. Newbury Park, CA: Sage.

Hollmann, R. W. \& Tansik, D. A. 1977. A lifecycle approach to management by objectives. The Academy of Management Review, 2(4):678-683

House, R.J. 2006. A 1976 theory of charismatic leadership. In Pierce, J.L. \& Newstrom, J.W. (Eds.) Leaders \& the leadership process: readings, self-assessments, \& applications. 4th ed. New York: McGraw-Hill.

Howell, J.M., \& Shamir, B. 2005. The role of followers in the charismatic leadership process: relationships and their consequences. Academy of Management Review, 30, 96-112.

Kaplan, R. S. \& Norton, D. P. 1995. Translating Strategy into Action: The Balanced Scorecard. Boston, MA: Harvard Business School Press.

Katz, D. \& Kahn, R. L. 1978. The Social Psychology of Organizations 2e. New York: Wiley.

Kluckohn, F. \& Strodtbeck, F. 1961. Variations in Value Orientation. Westport, CT: Greenwood Press. 
Kihlstrom, J.F., Cantor, N., Albright, J.S., Chew, B.R., Klein, S.B., \& Niedenthal, P.M. 1988. Information processing and the study of the self. In Berkowitz, L. (ed.) Advances in experimental social psychology. New York: Academic Press.

Lane, H. W. \& DiStephano, J. J. 1992. The impact of culture on management. In International Management Behaviour 2e. Boston: PWS Kent.

Locke, E. A. \& Latham, P. G. 1990. A Theory of Goal Setting and Task Performance. Englewood Cliffs, NJ: Prentice Hall.

Lynch, R. G. 1977. Management by Objectives. North Carolina: Chapel Hill School of Government.

Mayes, B. T. \& Allen, R. W. 1977. Toward a definition of organizational politics. The Academy of Management Review, 2(4):672-678

Mead, M. 1928. Coming of Age in Samoa. New York: Morrow.

Oakes, P. J. \& Turner, J. C. 1980. Social categorisation and intergroup bias: Does minimal intergroup discrimination make social identity more positive? European Journal of Social Psychology, 10:259-301.

Parsons, T. \& Shils, E. A. 1951. Toward a General Theory of Action. Cambridge, MA: Harvard University Press.

Podsakoff, P.M., MacKenzie, S.B., Moorman, R.H., \& Fetter, R. 1990. Transformational leader behaviors and their effects on followers' trust in leader, satisfaction, and organizational citizenship behaviors. The Leadership Quarterly, 1, 107-142.

Porter, M. E. 2007. Toward a dynamic theory of strategy. Strategic Management Journal, 12 (S2).

Porter, M. E. (ed.). Competition in Global Industries. Boston: Harvard Business School Press, 1986.

Robinson, D. A. 2010. The mad, the bad and the sad - personality disorders in firms. In Hill, R. (ed.), Personality and Individual Differences: Current Directions. Bond University Press.

Robinson, D. A. 2008. Keeping pace with change in SMEs - Creating and maintaining congruence and consistency in trans-national entrepreneurial firms. International Journal of Entrepreneurship and Innovation Management, 8(3):272-285.

Robinson, D. A., Davidsson, P. van der Mescht, H. \& Court, P. 2007. How entrepreneurs deal with ethical challenges - an application of the Business Ethics Synergy Star. Journal of Business Ethics, 71(4): 411-423.

Roy, B., Kerry, K., \& Kip, V. W. 1995. Energy Taxation as a Policy Instrument to Reduce $\mathrm{CO}_{2}$ Emissions: A Net Benefit Analysis. Journal of Environmental Economics \& Management. Vol. 29 (1): 1-24.

Senge, P. 1991. The $5^{\text {th }}$ Discipline: The art and practice of the learning organization. New York: Wiley.

Sorrentino, R. M. \& Higgins, E. T. (eds.). 1986. Handbook of Motivation and Cognition: Foundations of social behaviour. New York: Guilford.

Stryker, S. 1980. Symbolic Interactionism: A social structural version. Menlo Park, CA: Benjamin/Cummings.

Tajfel, H. 1978. Differentiation Between Social Groups: Studies in social psychology of intergroup relations. London: Academic Press.

Tajfel, H., Flament, C., Billig, M. G. \& Bundi, R. F. 1971. Social categorization and intergroup behaviour. European Journal of Social Psychology 1:149-177.

Triandis, H. 1989. Cross-cultural studies of individualism and collectivism. In Berman, J. (Ed). Nebraska Symposium on Education. Lincoln: University of Nebraska.

Turner, J.C. 1985. Social categorization and self-concept: A social-cognitive theory of group behaviour. In Lawler, E.J. (Ed.) Advances in group processes: Theory and research. Greenwich, CT: JAI Press 
Turner, J.C., Hogg, M.A., Oakes, P.J., Reicher, S.D., \& Wetherell, M. (1987). Rediscovering the social group: A self-categorization theory. Oxford: Blackwell

United Nations (Brundtland Report). 1987. Our Common Future, World Commission on Environment and Development (WCED)

Walumbwa, F.O. \& Schaubroeck, J. (2009). Leader personality traits and employee voice behaviour: mediating roles of ethical leadership and work group psychological safety. The Journal of Applied Psychology, 94, 1275-1286.

Witkin, H. A. \& Berry, J. W. 1975. Psychological differentiation in cross-cultural perspective. Journal of Cross-Cultural Psychology, 6(1):4-87

Witkin, H. \& Goodenough, D. R. 1977. Field behaviour and interpersonal behaviour. Psycholoical Bulletin, 84(4):661-689.

Yukl, G. 2008. How leaders influence organizational effectiveness. The Leadership Quarterly, 19, 708-722.

Yuk1, G. 2009. Leading organizational learning: Reflections on theory and research. The Leadership Quarterly, 20, 49-53. 